\title{
USE OF UIOT FOR OFFSHORE SURVEYS THROUGH AUTONOMOUS VEHICLES
}

\author{
Pedro Jose Bernalte Sanchez ${ }^{1}$ \\ Fausto Pedro García Márquez ${ }^{\star 1}$ \\ Shashank Govindara ${ }^{2}$ \\ Alexandru But ${ }^{2}$ \\ Benjamin Sportich ${ }^{2}$ \\ Simone Marini ${ }^{3}$ \\ Valter Jantara Junior ${ }^{4}$ \\ Mayorkinos Papaelias ${ }^{5}$ \\ ${ }^{1}$ University of Castilla-La Mancha, ETII Campus Universitario sn, Spain \\ ${ }^{2}$ Space Applications Services NV/SA, Brussels, Belgium \\ ${ }^{3}$ Institute of Marine Sciences, National Research Council of Italy (CNR), La Spezia, Italy \\ ${ }^{4}$ University of Birmingham, United Kingdom \\ ${ }^{5}$ School of Metallurgy and Materials, The University of Birmingham, United Kingdom
}

*Corresponding author:faustopedro.garcia@uclm.es (F.P.G. Márquez)

\begin{abstract}
The ENDURUNS project is a European Research project of the Horizon 2020 framework, which has as its main objective to achieve the optimum and intelligent use of green hydrogen energy for long-term ocean surveys. The ENDURUNS system comprises an Unmanned Surface Vehicle (USV) and an Autonomous Underwater Vehicle (AUV) with gliding capability. The power pack of the USV integrates Li-ion batteries with photovoltaic panels, whilst the AUV employs Li-ion batteries and a hydrogen fuel cell. It is essential to develop a continuous monitoring ca-pability for the different systems of the vehicles. Data transmission between the devices onboard presents challenges due to the volume and structure of the different datasets. A telecommunications network has been designed to manage the operational components considered in the project. The autonomous vehicles perform measurements, providing their position and other data wirelessly. The system will generate a great volume of various signals during the survey. The Remote Control Centre needs to be interfaced with the vehicles in order to receive, manage and store the acquired data. An Underwater Internet of Things (IoT) platform is designed to establish efficient and smart data management. This study presents an exhaustive survey to analyse the telecommunication systems employed in the autonomous vehicles, including the back-end, user interface and mobile units. This paper presents the novel design of the hardware and software structure of the ENDURUNS project with regard to the literature, where its components and their in-terconnection layers are detailed, which is a novel scientific and technological approach for autonomous seabed surveying in deep oceans or in coastal areas.
\end{abstract}

Keywords: Underwater Internet of Things (UIoT); autonomous underwater vehicles; unmanned surface vehicles; clean energy; data management; data transmission

\section{INTRODUCTION}

Ocean exploration is currently one of the most ambitious challenges in marine research. The greater part of the oceans $(\sim 75 \%)$ is yet to be surveyed [1]. There are various initiatives from governments and organisations, e.g., the International Hydrographic Commission or Intergovernmental Oceanographic Commission of UNESCO, for promoting submarine mapping and exploration, such as "Seabed 2030" [2]. ENDURUNS [3] is a research project to develop and demonstrate a long-endurance sea surveying autonomous unmanned vehicle with gliding capability powered by renewable energy. The project seeks to promote an enhanced monitoring capability of the oceans whilst employing advanced analytics coupled with extended operational endurance thanks to the hydrogen stored onboard, which will be used to recharge the batteries whenever required [4]. The ENDURUNS project is thus based on the use of autonomous marine vehicles for submarine mapping and inspection based 
on the use of clean energy. The power supply for the unmanned surface vehicle supporting the AUV glider is based on solar energy in combination with hydrogen fuel cells [5]. The use of hydrogen fuel cells on the AUV glider, capable of operating up to a depth of $6 \mathrm{~km}$, coupled with the unmanned surface vehicle in the role of the mothership, is novel and has not been attempted previously. Depending on the type of the mission, the energy consumption profile will vary. Since the AUV can be scaled up or scaled down, different amounts of hydrogen can be stored onboard and using different hydrogen storage options, including pressure vessels up to 700 bar, a liquid hydrogen storage tank or metal hydrides. Thus, extended performance can be achieved as required by the mission profile.

Underwater observation systems like ENDURUNS meet the growing demand for technological improvement in ocean exploration and monitoring aimed at increasing our understanding of the ocean interior for a valuable number of scientific, industrial and political reasons $[6,7]$. Deep water exploration and new data collection in this domain are of special interest to provide new insights into a variety of geological and ecological processes $[8,9]$, such as underwater hydrocarbons exploration, offshore carbon capture and storage, exploitation of deep-sea mineral resources, as well as for seafloor observatories [10-13]. At the same time, political drivers push toward the implementation of new coordinated marine monitoring programmes for establishing, preserving and restoring relevant Marine Protected Areas, as stated in the EU Marine Strategy Framework Directive (2008/56/EC). To satisfy all the interests in marine observation, better seabed mapping resolution is needed to increase the data accuracy for geohazard analysis (e.g., landslides, fluid escape features, mobile substrates), environmental impact assessments and monitoring (e.g., leaking hydrocarbons/CO2 and repeated monitoring of benthic habitats and ecosystems to protect marine biodiversity). In this context, it is indicative that the General Bathymetric Chart of Oceans (GEBCO) [14], operating under the auspices of the International Hydrographic Organization (IHO) and the Intergovernmental Oceanographic Commission (IOC) of UNESCO $[15,16]$, has set the objective to promote international collaboration for facilitating the complete mapping of the ocean floor by 2030, under the "Seabed 2030" initiative [14]. Charting the oceans and evaluating their resources is of great importance also to the global economy and societal security, since it provides direct information to generate more reliable climate-change models and a sustainable food production chain, understand the quality and status of sea habitats, or explore new offshore energy and mining resources [17].

The large volumes of data collected by the ENDURUNS sensors for the seabed mapping [3] are a bottleneck for realtime or quasi-real-time monitoring operations and bring the challenges of data analytic capacity and transmission. Therefore, the interpretation of signals and the generation of new knowledge of societal relevance, based on these vast and complex data, can only be achieved with the use of appropriate technological developments capable of detecting and extracting useful information from the collected data, with the aim of easing the quasi-real-time communication activities between the observation system and the data end user $[18,19]$.
The subsea telecommunications infrastructure is less accessible than on land. For this purpose, different platforms and systems are available for supporting the connectivity of the devices at the surface, e.g., the Automatic Identification System (AIS) [20] based on Very High Frequency (VHF) radio [21] or the wireless network technology Mobile ad-hoc Networks (MANETs), to give basic information such as identification, location, speed, course or destination of the marine devices, etc. [22]. For navigation, the Global Positioning System (GPS), Glogal'naya Navigatsionnaya Sputnikovaya Systema (GLONASS) [23], or new high-accuracy systems such as Precise Point Positioning (PPP) [24] in a Global Navigation System (GNSS) integration are employed [25]. Telecommunications underwater are more complex and complicated because electromagnetic signals are highly attenuated and therefore have a low transmission range [26]. Nevertheless, besides the consolidated acoustic communication approaches [27], new wireless electromagnetic and optical technologies for underwater data communication systems have been investigated [28]. Marine-related industries, e.g., offshore oil and gas, power transmission, logistics and offshore renewable energy, need precise and safe Information Technology (IT) systems for their future development and competitiveness $[29,30]$. The advances in robotics and sensor technologies allow efficient monitoring and promote the development of highly complex systems and applications [31-33]. The telematic and wireless control of systems provides broad and flexible configuration of industrial and technical processes [34]. These issues have been taken into account in the ENDURUNS project, developing a complex and robust connection network to ensure monitoring and management of different devices.

In the context of the Industry 4.0 revolution, the Internet of Things (IoT) term was developed in the 1990s, being associated with new concepts such as smart city/smart industry [35]. It refers to the capability of making content and services understandable by devices without human involvement. It is leading social, political, commercial and industrial changes. The process of digitisation is a strategic and economic key for any government and company, leading to increasing the volume, and variety, of data (known as Big Data) [35]. Nevertheless, the model and design of the land-based IoT cannot be adopted directly in the ocean exploration context. Therefore, the Underwater Internet of Things (UioT) model has been adopted for defining smart networks of interconnected underwater and land-based objects, possibly coupled with self-learning and intelligent computing services.

Big Data was defined by IBM in 2012 [36] by the properties of the volume, velocity and variety of the dataset. Big Data analysis requires the development of deep knowledge of their installations and operations together with robust and complex algorithms [37, 38]. The design of a unified data architecture and online applications is a challenge [39]. The ENDURUNS project considers the Remote Monitoring and Control Centre (RMCC) as a node for the implementation of a UIoT platform, allowing a novel interface for the control and communication of surface and submarine vehicles during their mission. This methodology would enable an online monitoring and data analysis. 


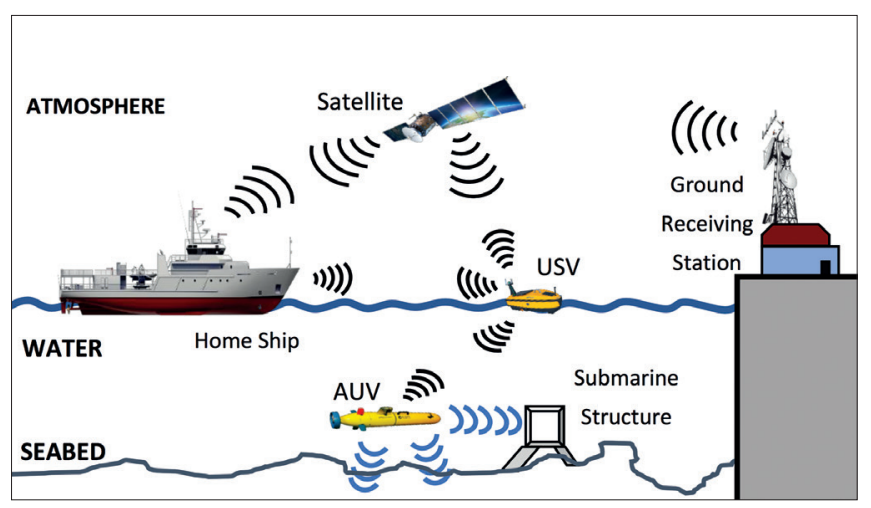

Fig. 1. Telecommunications strategy in ENDURUNS project [41]

The main contributions of this paper are summarised as follows:

- An exhaustive survey is presented to analyse the communication systems employed in autonomous underwater vehicles (AUV) and unmanned surface vehicles (USV), including the backend, user interface and mobile units.

- The details of the ENDURUNS project telecommunications systems are presented. The novel design of the hardware and software architecture used in the project's installations according to the literature, describing the elements and devices parts and their interconnection layers, is discussed.

- The use of UIoT for the ENDURUNS parameters and systems monitoring is investigated. This technology is employed for intelligent data management through online platforms and applications.

The rest of the paper is as follows: Section 2 presents the communication system considered in the ENDURUNS project, describing the data transmission strategy between the devices. Sub-section 2.1 describes the IT system and the data network architecture. The project software and hardware configurations and functionality layers are also discussed. Back-end and User Interface Blocks are described and analysed in Subsections 2.2 and 2.3, while Sub-section 2.4 explains the devices' (AUV and USV) IT blocks and associated infrastructure. Sub-section 2.5 details the emergency contingency plan for data retrieval in the case of failure. Section 3 studies the implementation and application of UIoT for marine and submarine surveys and inspections through autonomous vehicles, and also the implementation of UIoT systems within ENDURUNS. Finally, the main conclusions are presented in Section 4.

\section{COMMUNICATIONS SYSTEM IN ENDURUNS}

The survey performance of the ENDURUNS project is given through the integration of the USV with the AUV. Both vehicles use clean energy sources. The real-time piloting and monitoring approach of the vehicles is represented by the communications infrastructure shown in Fig. 1. This infrastructure is based on the Remote Monitoring Control Centre (RMCC), in which the hardware and physical user interface are hosted, together with the data storage and network devices. A similar approach has been employed in MUNIN [40].

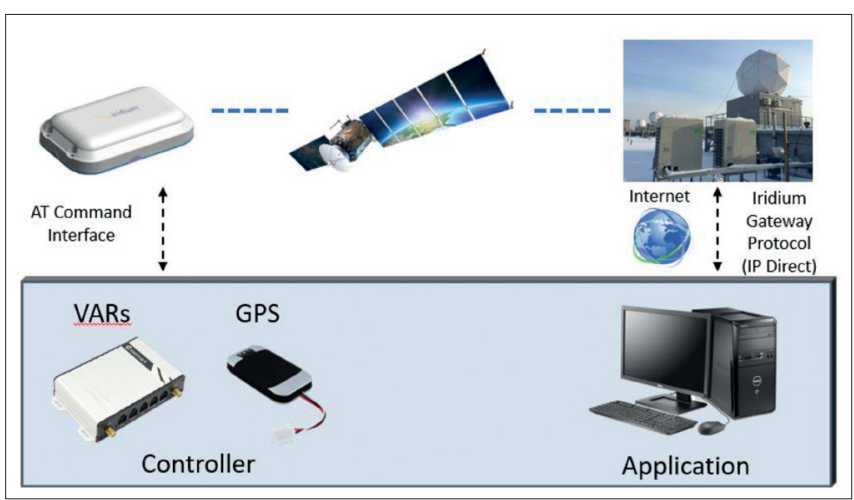

Fig. 2. ENDURUNS data transmission schematic

The data transmission between the components of the system will be supported by satellite and technologies such as VHF, wireless and positioning (Fig. 2). These transmissions are performed across both water and air. AUV data acquisition from subsea will be sent to the USV through an acoustic communication system when the AUV is submerged, and through a wireless communication system when the AUV is at the sea surface. The USV saves and processes the information received from the AUV and sends it through satellite communication to the RMCC.

\section{SYSTEM ARCHITECTURE}

The intercommunication components design has been done considering the long-range transmission, data volume, data heterogeneity transmission speed and the transmission medium between devices [42]. It is possible to define various communication technologies depending on the functionality or attribution of them. The power source, together with the energy consumption, are the main bottleneck of the system. For the wireless connectivity, the most common technology applied is the Internet through Transmission Control Protocol (TCP) properly configured for the ports, modems or Wifi AP (Access Point) of the project devices [43]. Ethernet in the AUV and USV uses Local Area Net (LAN) connections [44] and wireless LAN (WLAN) [45]. Weighted data transfer buses, Universal Serial Bus (USB) or Height Definition Multimedia Interface (HDMI) are used to connect different sensors from/to the process and

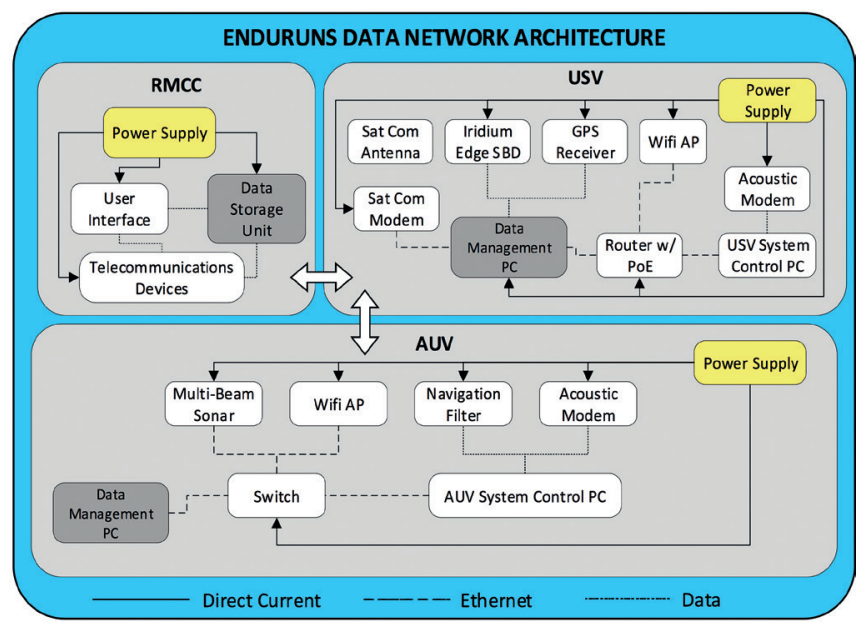

Fig. 3. ENDURUNS data network architecture 


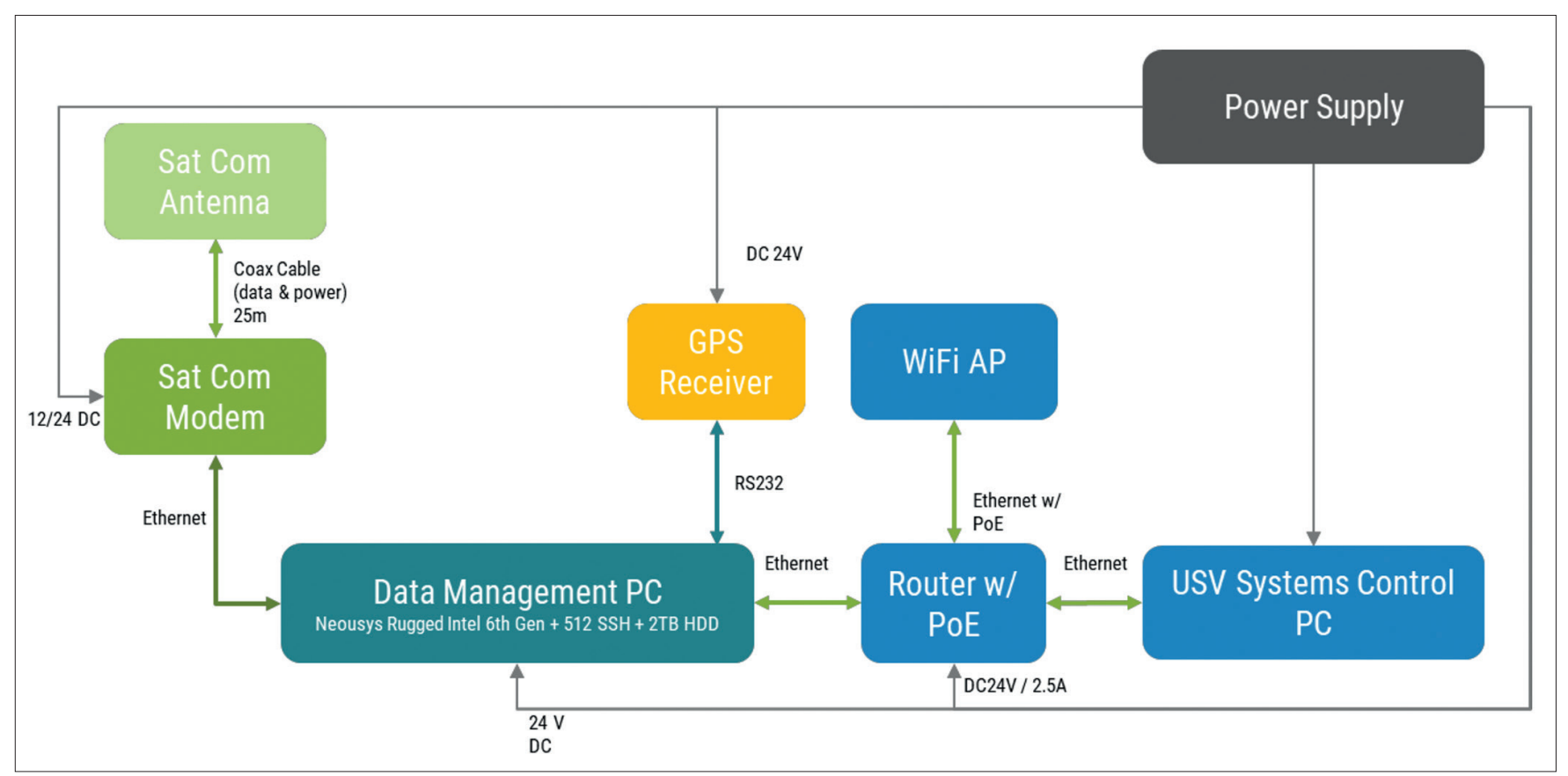

Fig. 4. USV data management hardware

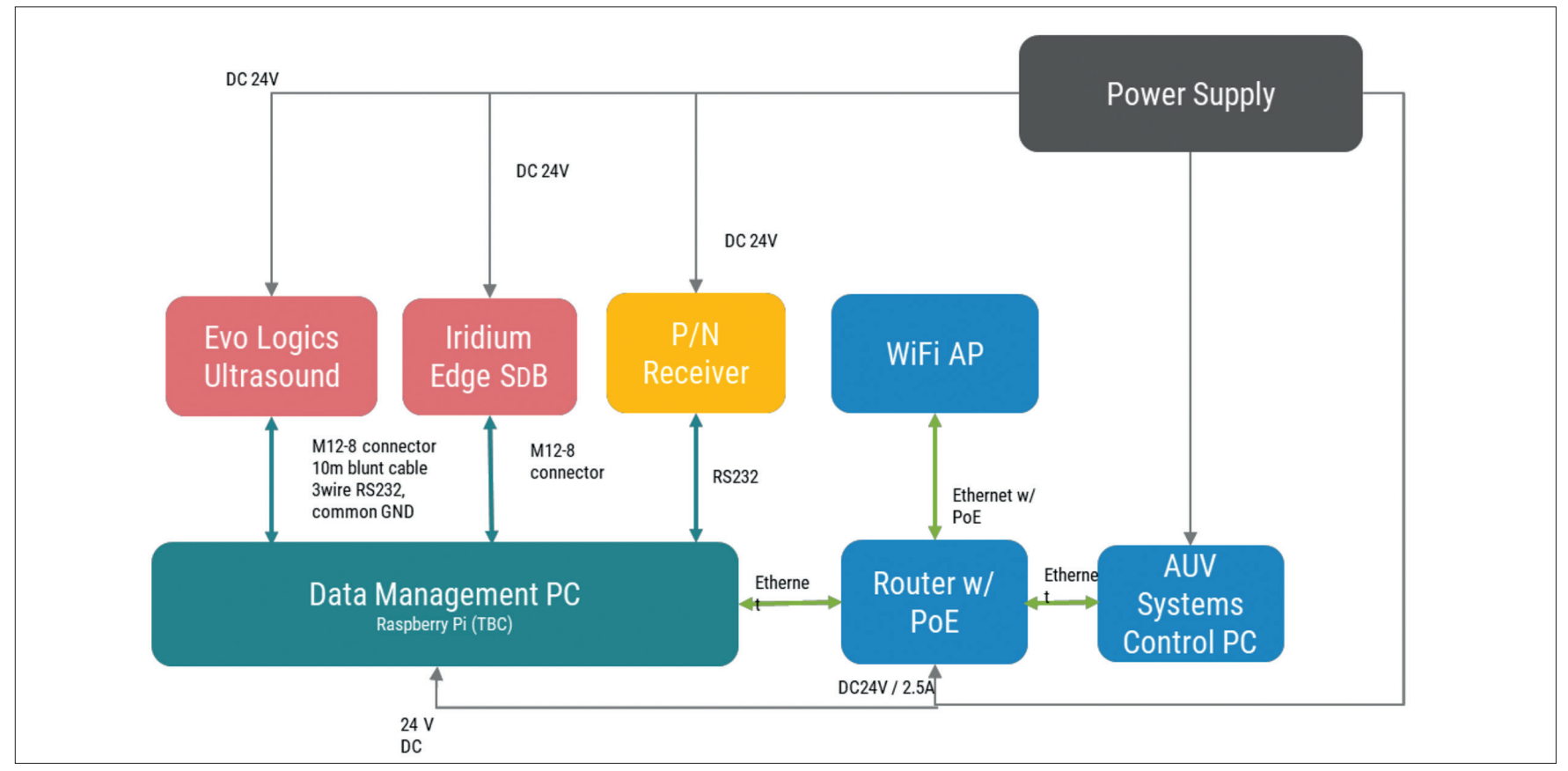

Fig. 5. AUV data management hardware

storage units [46]. A detailed block diagram of the data network architecture is presented in Fig. 3.

A pyramidal communications structure is considered between devices, the AUV being in the base and the RMCC in the top. The USV works as a link and port between them, managing the long-range data transfers and the energy source. There are some research studies discussing offshore communication nodes with physical platforms, e.g., between surface buoys and underwater points, to support a high-speed connection net [47]. In this case, the underwater wireless sensor network has a fixed geometry, providing reference points for the AUV and USV missions [48]. One of the applications of the ENDURUNS vehicle system is seabed mapping, where the AUV is equipped with an acoustic sonar and optical sensors producing a complete three-dimensional seafloor vision. That generates a high volume of data [49]. In this case, it is necessary to install modems on both the USV (Fig. 4) and the AUV (Fig. 5) for ensuring real-time navigation control and precise data geo-referencing.

The system communication specifications were defined in terms of transmission systems, devices connections, transmission environment, data speed rate, and transmission ranges. These components were proposed for the optimal performance in marine environment operations according 
Tab. 1. Data transfer specifications

\begin{tabular}{|c|c|c|c|}
\hline TRANSMISSION SYSTEM & ENVIRONMENT & MAX. SPEED RATE & RANGE \\
\hline Acoustic waves, Very Low Frequency (VLF) [50] & Water & 300 kbps [51] & Short/medium distance \\
\hline Ultrasound $[52,53]$ & Water & 35 kbps [53] & In contact/short distance \\
\hline GEO satellite [54] & Air/Water & $492 \mathrm{kbps}$ & Medium/long distance \\
\hline Iridium Short Burst Data (SBD) / INMARSAT [55] & Air & $\begin{array}{l}128 \mathrm{kbps} \\
384 \mathrm{kbps}\end{array}$ & Medium/long distance \\
\hline Internet (3G,4G, LTE) [56] & Air & 10 Mbps [57] & Medium/longdistance \\
\hline Ethernet (LAN/WLAN) $[58,59]$ & Air/Water & $\begin{array}{l}300 \text { Mbps [60] } \\
1 \text { Gbps [61] }\end{array}$ & $\begin{array}{c}\text { In contact } \\
\text { Short/medium distance }\end{array}$ \\
\hline VHF[62] & Air & $9.6 \mathrm{kbps}[63]$ & Long distance \\
\hline VDES (VHF Data Exchange System) [64] & Air & $302 \mathrm{kbps}[65]$ & Long distance \\
\hline HDMI [66] & Air/Water & 3,4 Gbps & In contact \\
\hline USB/USB type C $[67,68]$ & Air/Water & 10 Gbps [69] & In contact \\
\hline Microwave pinless [70] & Air/Water & 100 Mbps [71] & In contact \\
\hline
\end{tabular}

Tab. 2. ENDURUNS telecommunications set-up

\begin{tabular}{|c|c|c|c|}
\hline COMMU-NICA-TION PATH & ASSOCIATED TECHNOL-OGIES & DEVICES & FIGURES \\
\hline RMCC to USV & L Band satellite link mounted on the AUV & $\begin{array}{c}\text { Thales } \\
\text { VesseLINK }\end{array}$ & THALES \\
\hline RMCC to AUV & SDB satellite link mounted on the AUV & Iridium Edge & \\
\hline AUV to USV & WiFi link when AUV is on the surface & $\begin{array}{l}\text { WAV Link router AERIAL } \\
\text { HD4-AC1200 }\end{array}$ & \\
\hline AUV to USV & Acoustic link when the AUV is submerged & $\begin{array}{c}\text { EvoLogics Acoustic } \\
\text { Modem S2CR 18/34H/USBL }\end{array}$ & \\
\hline
\end{tabular}

to the current state-of-the-art technologies and recent technological advances (Table 1).

A trade-off between project requirements and communication limitations can be found in [72] to minimise the energy consumption of the AUV. In addition to the previous aspects, the size, weight, shape and price of the different systems have been taken into account to choose the most appropriate elements for the installation. The data exchange technologies employed in the ENDURUNS project are presented in Table 2 according to the communication paths designed between the vehicles and RMCC during the mission.

Christensen et al. [73] defined the internal layers and the IT configuration in the design of communication and control for swarms of aquatic surface drones. Fig. 6 shows the design adopted in ENDURUNS.

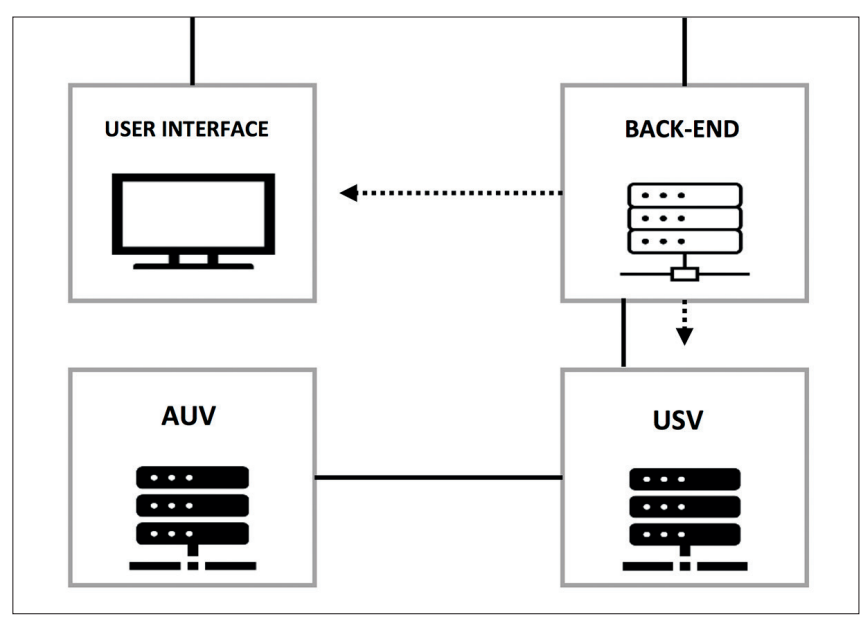

Fig. 6. Schematic diagram of IT structure 


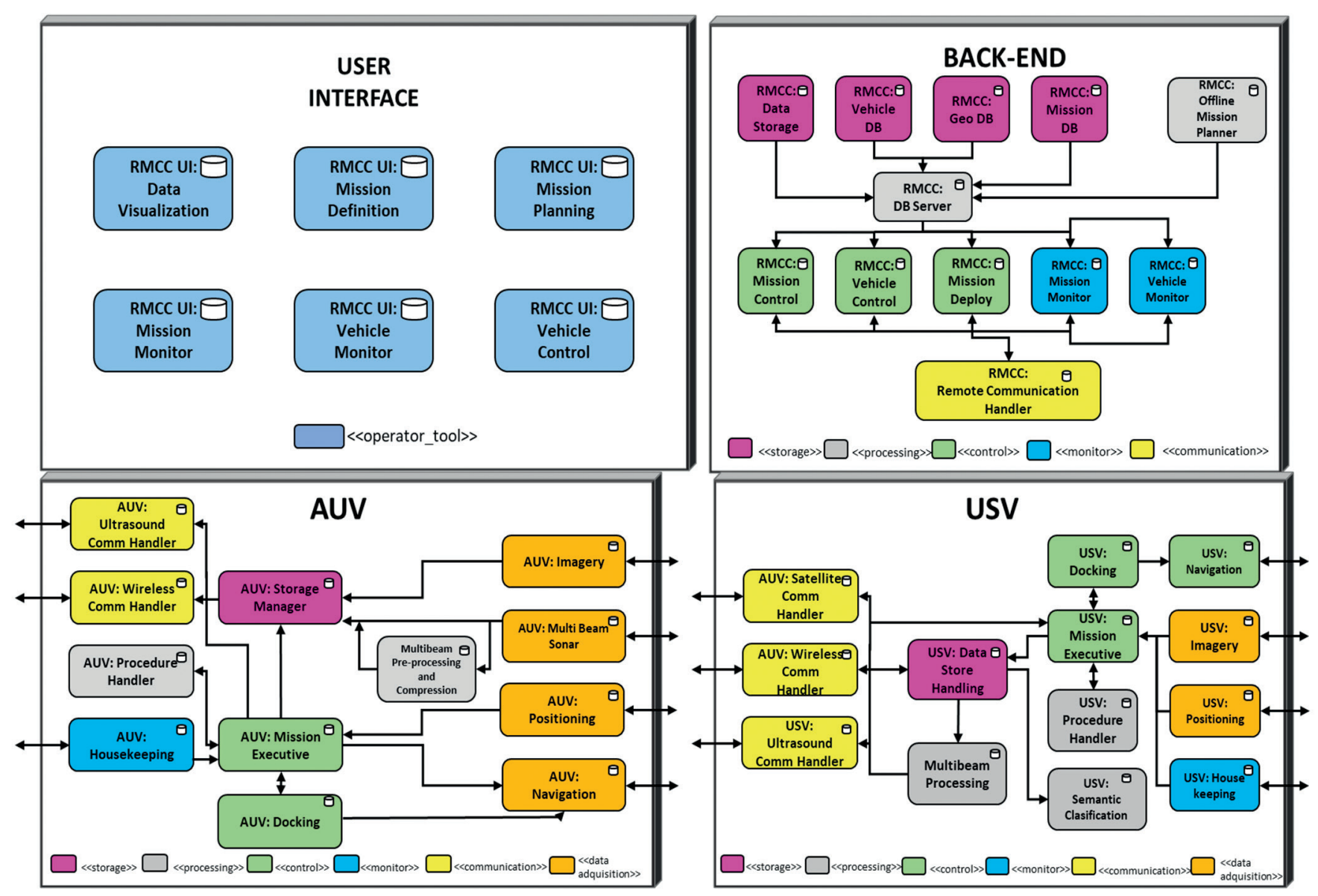

Fig. 7. RMCC and high-level visualisation

The following sections present each block with the different layers and structures shown in Fig. 6. They discusses the functionalities of each block according to the following: Data storage; Data processing; Control system; Monitoring; Communication system; Data acquisition; and Operator tools.

\section{BACK-END BLOCK}

The back-end block is a critical component in any IT system. This layer of the system is entrusted with managing the data inputs from the software used in the project. The back-end, or binary logic development, presents the black box for the project operations and coordination. This block is responsible for management of the hardware and software infrastructures for the correct data acquisition treatment, analysis and storage 74]. This block works for a UIoT in the ENDURUNS project, leading applications and online platforms with an intelligent condition monitoring [75]. Fig. 7 shows a scheme of the RMCC design and the high-level executive.

The RMCC is the reference physical unit for this block. The RMCC manages from the ground the rest of the mobile units and satellite connections of the project. One of the main functionalities layers of this block is the storage, due to the importance of the configuration of the project database and its infrastructure [76]. This layer is associated with the processing and control layers working for the operation of the vehicle in a mission programme [77]. Finally, there are two more layers in the backend configuration: a monitoring layer that shows the state of the mission and vehicles parameters, and the communication layer that holds the connectivity and data transmissions of the units and formats required in the project 78].

\section{USER INTERFACE BLOCK}

The user interface block is the high-level software tool to be integrated in the IT infrastructure, allowing the operator to manage the mission. Some studies about the online interface classify the system architecture modes between in-mission or post-mission analysis [79]. This block will be in the root of the RMCC, being the platform for the user interaction and monitoring. It is possible to define two main utility classes in this block: the visualisation, or monitoring applications, including project data visualisation and mission, vehicles, and units monitoring [80]; and the mission planner tools and the vehicles control, focused on the interface of the input and output parameters for the mission operations [81]. Fig. 8 shows a diagram of this block structure.

The mission planner tools, via the RMCC, also have the capacity to control and monitor the location of the vehicles through their sensors and the communications satellite. This leads to real-time monitoring by the operator or user, being useful in the case of mission changes or incidents. 


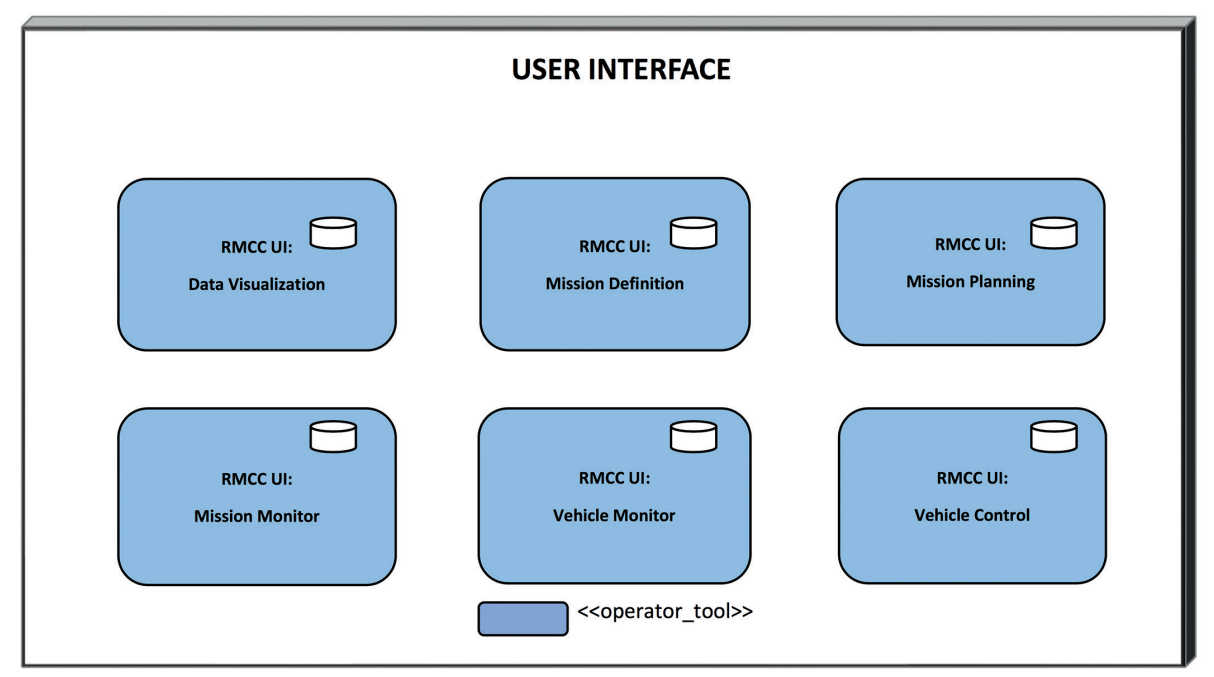

Fig. 8. User interface block visualisation

\section{MOBILE UNITS BLOCKS}

The block configurations for the AUV and USV have been considered, having similar architecture and use of technologies. The design of these blocks takes into account the role of each vehicle during the mission. The connectivity between the AUV and the USV ensures a double-link communication, the AUV being the vehicle which hosts the main data acquisition device. The block layers configuration reproduces the backend block principles [82]. Nevertheless, in this block there is a significant new functionality layer named data acquisition [83]. It manages the input data acquired in the inspection environment regarding the navigation of the vehicles [84], i.e., the input/output sequence for the control, processing or storage layer of the system. Related to the data transmission and communication layers, the ultrasounds handler, wireless handler, and satellite (this one only for the USV) are considered. The vehicle blocks also host a monitor and storage layer to develop the data from these devices.

The block configurations are included in the IT structure, a complex and coordinate system resumed in the four major blocks. The software and configuration have been designed according to the IT principles and functionalities [85].

\section{EMERGENCY CONTINGENCY PLAN FOR DATA RETRIEVAL}

AUVs are required to operate in complex and adverse conditions. In the event of a failure, an emergency contingency plan for easy retrieval of the data that has already been obtained must be in place. A backup of the collected data will be constantly updated via USB to a Secure Digital (SD) card. This SD card will be stored in a "bubble" which can be made of polymers such as polycarbonate (PC) or polyether ether ketone (PEEK), or metals such as aluminium or stainless steel. The choice of the bubble material will depend on the required depth for the mission. This "data bubble" will be powered by a small Li-ion battery. In an emergency, the USB connection will be turned off and the USB cable will be severed by an actuator, allowing for the release of the data bubble. The data bubble is buoyant and will float to the surface, where it will be retrieved by the USV.

\section{UIOT IMPLEMENTATION}

Nowadays, Industry 4.0 facilities are being employed in cases related to UIoT use in marine industry, e.g., in fishing exploitation management [86], navigation and localisation systems infrastructure or oceans data acquisition and cartography [21]. UIoT is beginning to be employed in some initiatives and projects [87], e.g., the European project SUNRISE [88]. The ENDURUNS project proposes a UIoT implementation based on an IT structure [89]. The integration of this novel technology assumes an evolution for the automation, real- time and web monitoring capability [90]. The combined use of UIoT with IT requires technical and high-level computation integration [91].

\section{TECHNOLOGIES AND INFRASTRUCTURES}

The sensors employed are configured together with the latest connectivity technologies to guarantee optimum performance $[92,93]$. Through the use of mobile networks, e.g., 3G, Long Term Evolution (LTE), 4G [56], MANETs, wireless and satellite supports, it has been possible to develop a web application, similar to those presented in $[94,95]$. The acquisition of massive data from the sensor layer is managed by the user. Therefore, the security, privacy and integrity of data are important.

Wireless Sensor Networks (WSN) are also considered in UIoT applications [96], with the aim of analysing the external information. This physical platform consists in the distribution of nodes (low-power devices) in the study area, allowing monitoring or support tasks for the principal devices or vehicles [97]. The node input information is acquired and sent by wireless means to the RMCC or interface devices. Furthermore, these nodes can work as storage and process units [98]. This technology appears in different topologies: the star mode (multiple peripheral nodes around the central node); tree mode (a variation of the star mode having ordinary nodes, 
partner nodes and root nodes); mesh mode (multiple routes, each node working as a router); and hierarchical mode (head nodes with a subordinate node group) [33]. The configuration and use of this technique considers a WSN protocol compatible with the main objective [99]. For the submarine environment, a specific communication technology with the same principle as WSN has been defined. This technology uses the underwater acoustic sensor networks (UWSNs) [100] by locating the mentioned nodes in the seabed [101].

The Radio Frequency Identification (RFID) technique has also been considered [102]. This method is analogous to the commonly used barcode identification; nevertheless, this new format allows advantages such as storage capacity or programming features [103]. The RFID would be useful to establish a database for different applications, managing devices or sensors by the user or RMCC.

\section{CASE STUDY}

The configuration of the ENDURUNS technology is focused on online monitoring between the RMCC and both the AUV and CSV vehicles. During the mission, the offshore meteorology or environment conditions could affect the mission. To address this issue, it employed a web application based on the outcome of state agencies or international organisations for weather condition monitoring [104]. Furthermore, a WSN is established with strategic localisation points. These physical nodes work as an interconnection net between the AUV and USV, providing a communication system for data storage and satellite data transmissions. The WSN leads to exploiting the existing ocean surface or submarine infrastructures such as buoys nets, oil platforms or underwater pipelines [105]. The definition of the submarine transmission protocols, the node routing technologies and its constraints are considered in the UWSN application [106].

The RFID technology is employed in the AUV and USV [107], having the possibility of increasing the number of vehicles in the mission. It is suggested that, for multiple vehicles working and surveying at the same time, RFID should be used to report the collected information to the system [108].

The integration of the UIoT platform in the ENDURUNS project architecture is done by a back-end review or upgrade. The UIoT synchronises the IT layers with the AUV and USV, and RMCC devices. It is possible to establish different system architecture levels between the data layer (commonly using the cloud platform) [109], the communication layer (telecommunications networks) [110] and the sensing layer (the UIoT technologies implemented and the devices' physical infrastructures) [111]. The schematic diagram shown in Fig. 9 considers the UIoT architecture used in the ENDURUNS project. The back-end also includes characterisation in the sensing, gateway [112] and server blocks [113]. For the safety of the project performance, it is important to develop a security protocol and tools to guarantee the protection of the system [114]. The volume of marine data has increased substantially in recent years. Therefore, big data protection and storage create a need to design a safe system using technologies such as blockchain or complex encryption [115].

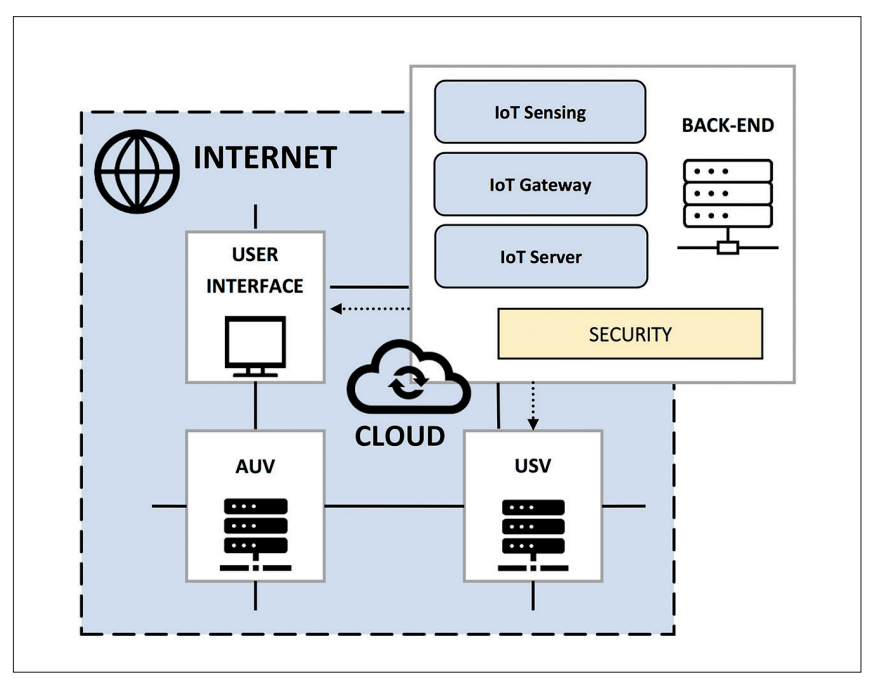

Fig. 9. Proposed UIoT architecture for the ENDURUNS project

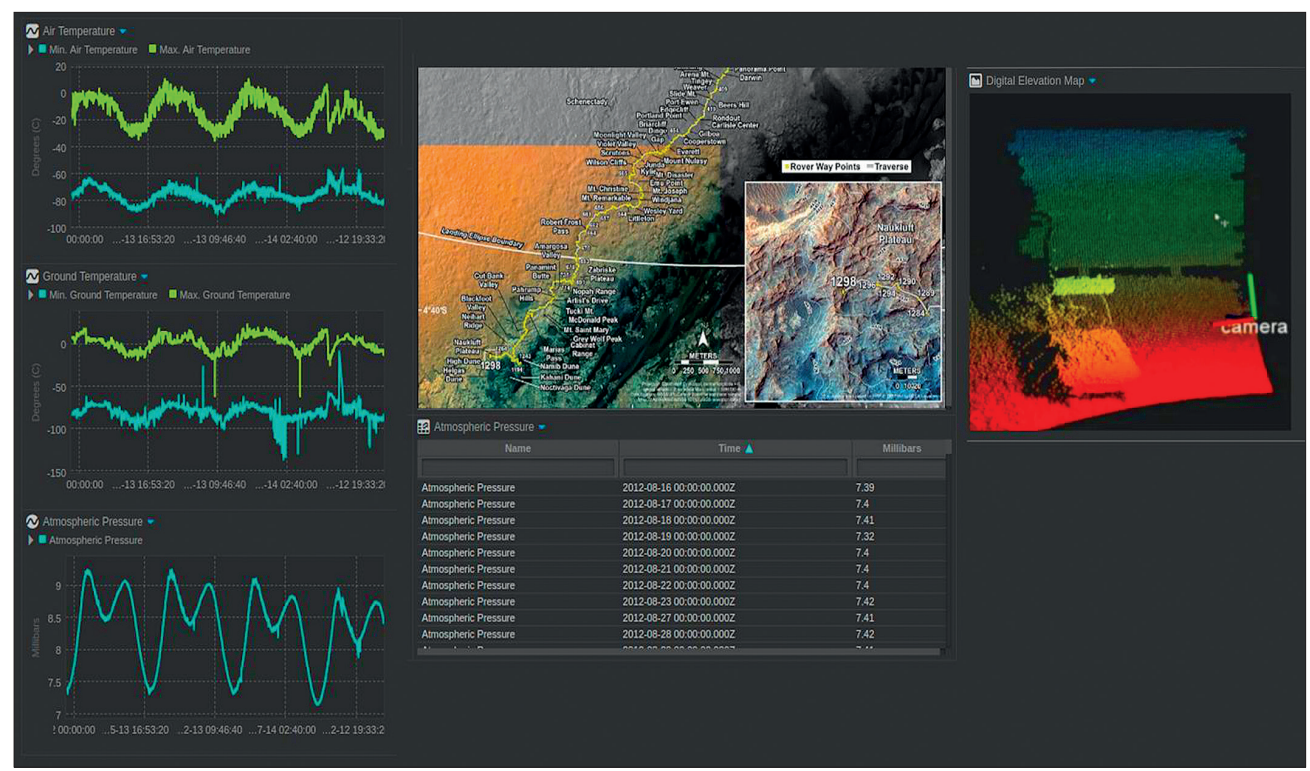

Fig. 10. Example of monitoring interface 


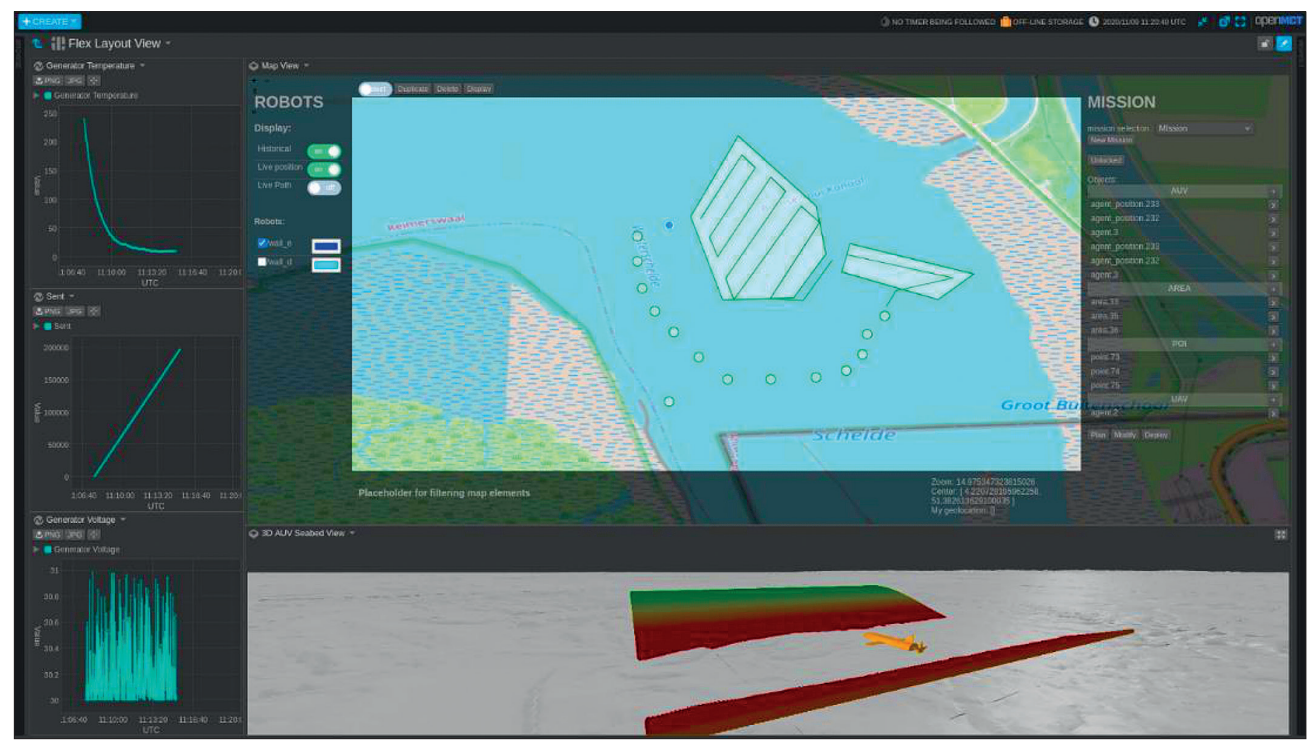

Fig. 11. Example of routing interface

Fig. 10 shows an example of the monitoring results, plots of some variables such as the minimum and maximum temperatures in the ground and air, atmospheric pressure, a surface map with key points and other details, and a submarine photo of an object.

Fig. 11 shows an example of routing together with some signals such as the generator temperature, generator voltage, route map, details of the mission map, etc.

The UIoT implementation needs a test process or proven validation to ensure the correct operation of the project [116]. The implementation, optimisation and maintenance of the process could be supported by external experts or specialist enterprises of the UIoT sector and government permissions, involving outsourced facilities in many cases [117]. The UIoT evolution for this project involves a measurable economic investment on account of the software, hardware, and the procurement of IT infrastructures [118].

\section{CONCLUSIONS}

In relation to the exploration of the ocean and offshore surveys, the European Commission has promoted initiatives and investment in renewable energies and marine industrial modernisation. The ENDURUNS project, part of the Horizon 2020 programme, is attempting to realise the offshore and seabed monitoring and inspection capability using clean energies and guaranteeing an endurance optimisation of the project devices.

To understand the project achievements, the system description and infrastructure configuration have been presented. The data network architecture performing the classification of the different hardware of the project and functional units (RMCC, USV and AUV) has been defined.

Based on this preliminary design, an intelligent system in the line of Industry 4.0 has been proposed. The use of UIoT in different marine industry sectors such as shipping, fishing, or navigation motivates the application of this technology in the project. UIoT is based in different technologies commonly used with this aim, considering sensors, storage, identification and communication layers. It allows for real-time monitoring of the system devices through modern wireless communications. In relation to the data analysis or big data, the project is able to process a large volume of information with the use of an online host such as the cloud. Finally, the survey area or exploration capacity is increased with the use of a multiple vehicles network, using tools of identification and coordination for the mission operations.

\section{ACKNOWLEDGEMENTS}

The work reported herewith has been supported by the European Project H2020 under the Research Grants H2020-MG-2018-2019-2020, ENDURUNS.

\section{CONFLICTS OF INTEREST:}

Authors must identify and declare any personal circumstances or interest that may be perceived as inappropriately influencing the representation or interpretation of reported research results. Any role of the funders in the design of the study; in the collection, analyses or interpretation of data; in the writing of the manuscript, or in the decision to publish the results must be declared in this section. If there is no role, please state "The funders had no role in the design of the study; in the collection, analyses, or interpretation of data; in the writing of the manuscript, or in the decision to publish the results".

\section{REFERENCES}

1. R. Goonesekere and Y. Guo, "Unmanned Underwater Drone Design for Ocean Exploration," in ASME 2018 International Mechanical Engineering Congress and Exposition, 2018.

2. L. Mayer, M. Jakobsson, G. Allen, B. Dorschel, R. Falconer, V. Ferrini, et al., "The Nippon Foundation-GEBCO seabed 
2030 project: The quest to see the world's oceans completely mapped by 2030," Geosciences, vol. 8, p. 63, 2018.

3. S. Marini, N. Gjeci, S. Govindaraj, A. But, B. Sportich, E. Ottaviani, et al., "ENDURUNS: An Integrated and Flexible Approach for Seabed Survey Through Autonomous Mobile Vehicles," Journal of Marine Science and Engineering, vol. 8, p. 633, 2020.

4. R. Veugelers, M. Cincera, R. Frietsch, C. Rammer, T. Schubert, A. Pelle, et al., "The impact of horizon 2020 on innovation in Europe," Intereconomics, vol. 50, pp. 4-30, 2015.

5. I. Segovia, A. Pliego, M. Papaelias, and F. P. G. Márquez, "Optimal Management of Marine Inspection with Autonomous Underwater Vehicles," in International Conference on Management Science and Engineering Management, 2019, pp. 760-771.

6. R. Danovaro, J. Aguzzi, E. Fanelli, D. Billett, K. Gjerde, A. Jamieson, et al., "An ecosystem-based deep-ocean strategy," Science, vol. 355, pp. 452-454, 2017.

7. S. Sokolov, A. Zhilenkov, A. Nyrkov, and S. Chernyi, “The use robotics for underwater research complex objects," in Computational intelligence in data mining, ed: Springer, 2017, pp. 421-427.

8. R. Danovaro, C. Corinaldesi, A. Dell'Anno, and P. V. Snelgrove, “The deep-sea under global change," Current Biology, vol. 27, pp. R461-R465, 2017.

9. A. Aguzzi, "'Broken access' publishing corrodes quality," Nature, vol. 570, pp. 139-140, 2019.

10. J. Aguzzi, D. Chatzievangelou, S. Marini, E. Fanelli, R. Danovaro, S. Flögel, et al., "New high-tech flexible networks for the monitoring of deep-sea ecosystems," Environmental science \& technology, vol. 53, pp. 6616-6631, 2019.

11. M. Rovere, A. Mercorella, E. Frapiccini, V. Funari, F. Spagnoli, C. Pellegrini, et al., "Geochemical and geophysical monitoring of hydrocarbon seepage in the Adriatic Sea," Sensors, vol. 20, p. 1504, 2020.

12. U. Neettiyath, B. Thornton, M. Sangekar, Y. Nishida, K. Ishii, A. Bodenmann, et al., "Deep-Sea Robotic Survey and Data Processing Methods for Regional-Scale Estimation of Manganese Crust Distribution," IEEE Journal of Oceanic Engineering, vol. 46, pp. 102-114, 2020.

13. M. Esposito, M. Martinez-Cabanas, D. P. Connelly, D. Jasinski, P. Linke, M. Schmidt, et al., "Water column baseline assessment for offshore Carbon Dioxide Capture and Storage (CCS) sites: Analysis of field data from the Goldeneye storage complex area," International Journal of Greenhouse Gas Control, vol. 109, p. 103344, 2021.
14. GEBCO, "General Bathymetric Chart of Oceans," Available online: https://www.gebco.net/ (accessed on June 2021). 2021.

15. IHO, "International Hydrographic Organization.," Available online: https://iho.int/ (Accessed on June 2021), 2021.

16. IOC, "Intergovernmental Oceanographic Commission.," Available online: http://www.ioc-unesco.org/ (Accessed June 2021), 2021.

17. R. B. Wynn, V. A. Huvenne, T. P. Le Bas, B. J. Murton, D. P. Connelly, B. J. Bett, et al., "Autonomous Underwater Vehicles (AUVs): Their past, present and future contributions to the advancement of marine geoscience," Marine Geology, vol. 352, pp. 451-468, 2014.

18. W. Shi, J. Cao, Q. Zhang, Y. Li, and L. Xu, "Edge computing: Vision and challenges," IEEE internet of things journal, vol. 3, pp. 637-646, 2016.

19. M. Jahanbakht, W. Xiang, L. Hanzo, and M. R. Azghadi, "Internet of underwater Things and big marine data analytics-A comprehensive survey," IEEE Communications Surveys \& Tutorials, 2021.

20. B. Shi, Y. Su, D. Zhang, C. Wang, and M. S. AbouOmar, "Research on Trajectory Reconstruction Method Using Automatic Identification System Data for Unmanned Surface Vessel," IEEE Access, vol. 7, pp. 170374-170384, 2019.

21. R. Al-Zaidi, J. Woods, M. Al-Khalidi, and H. Hu, "An iotenabled system for marine data acquisition and cartography," Transactions on networks and Communications, vol. 5, 2017.

22. R. Al-Zaidi, J. C. Woods, M. Al-Khalidi, and H. Hu, "Building Novel VHF-Based Wireless Sensor Networks for the Internet of Marine Things," IEEE Sensors Journal, vol. 18, pp. 2131$2144,2018$.

23. R. M. Alkan, M. H. Saka, İ. M. Ozulu, and V. İlçi, "Kinematic precise point positioning using GPS and GLONASS measurements in marine environments," Measurement, vol. 109, pp. 36-43, 2017.

24. T. Liu, Y. Yuan, B. Zhang, N. Wang, B. Tan, and Y. Chen, "Multi-GNSS precise point positioning (MGPPP) using raw observations," Journal of geodesy, vol. 91, pp. 253-268, 2017.

25. J. Tegedor, O. Ørpen, T. Melgård, D. Łapucha, and H. Visser, "G4 Multi-constellation Precise Point Positioning service for high accuracy offshore navigation," TransNav: International Journal on Marine Navigation and Safety of Sea Transportation, vol. 11, 2017.

26. N. Goyal, M. Dave, and A. K. Verma, "Protocol stack of underwater wireless sensor network: classical approaches 
and new trends," Wireless Personal Communications, vol. 104, pp. 995-1022, 2019.

27. A. Song, M. Stojanovic, and M. Chitre, "Editorial underwater acoustic communications: Where we stand and what is next?, IEEE Journal of Oceanic Engineering, vol. 44, pp. 1-6, 2019.

28. K. F. Haque, K. H. Kabir, and A. Abdelgawad, "Advancement of Routing Protocols and Applications of Underwater Wireless Sensor Network (UWSN) - A Survey," Journal of Sensor and Actuator Networks, vol. 9, p. 19, 2020.

29. N. Zhang, "Architecture Research and Design of the IoT Middleware for Marine Logistics," Journal of Coastal Research, vol. 94, pp. 196-199, 2019.

30. F. P. G. Márquez, I. P. G. Pardo, and M. R. M. Nieto, "Competitiveness based on logistic management: a real case study," Annals of Operations Research, vol. 233, pp. 157-169, 2015.

31. M.-H. Jeon, Y.-J. Jo, S.-H. Kim, and C.-H. Oh, "Design of GPS based LPWA module for marine IoT applications," presented at the INTERNATIONAL CONFERENCE ON FUTURE INFORMATION \& COMMUNICATION ENGINEERING, 2018.

32. J. Aguzzi, D. Chatzievangelou, S. Marini, E. Fanelli, R. Danovaro, S. Flögel, et al., "New High-Tech Flexible Networks for the Monitoring of Deep-Sea Ecosystems," Environmental Science \& Technology, vol. 53, pp. 6616-6631, 2019/06/18 2019.

33. J. Aguzzi, D. Chatzievangelou, M. Francescangeli, S. Marini, F. Bonofiglio, J. del Rio, et al., "The hierarchic treatment of marine ecological information from spatial networks of benthic platforms," Sensors, vol. 20, p. 1751, 2020.

34. Y. Wu, X. Ta, R. Xiao, Y. Wei, D. An, and D. Li, "Survey of underwater robot positioning navigation," Applied Ocean Research, vol. 90, p. 101845, 2019.

35. C. A. Medina, M. R. Pérez, and L. C. Trujillo, "IoT Paradigm into the Smart City Vision: A Survey," in 2017 IEEE International Conference on Internet of Things (iThings) and IEEE Green Computing and Communications (GreenCom) and IEEE Cyber, Physical and Social Computing (CPSCom) and IEEE Smart Data (SmartData), 2017, pp. 695-704.

36. B. Xiao, R. Rahmani, L. Yuhong, D. Gillblad, and T. Kanter, "Intelligent data-intensive IoT: A survey," in 2016 2nd IEEE International Conference on Computer and Communications (ICCC), 2016, pp. 2362-2368.

37. C. I. Noshi, A. I. Assem, and J. J. Schubert, "The Role of Big Data Analytics in Exploration and Production: A Review of Benefits and Applications," in SPE International Heavy Oil Conference and Exhibition, 2018.
38. L. Guidi, A. Fernàndez-Guerra, C. Canchaya, E. Curry, F. Foglini, J.-O. Irisson, et al., "Big data in marine science," Marine Board Future Science Brief, 2020.

39. R. Kumar, S. P. Singh, and K. Lamba, "Sustainable robust layout using Big Data approach: A key towards industry 4.0," Journal of Cleaner Production, vol. 204, pp. 643-659, 2018/12/10/ 2018.

40. C. Fraunhofer, "Maritime unmanned navigation through intelligence in networks," Fraunhofer CML: Hamburg, Germany, 2016.

41. P. J. B. Sánchez, M. Papaelias, and F. P. G. Márquez, "Autonomous underwater vehicles: Instrumentation and measurements," IEEE Instrumentation \& Measurement Magazine, vol. 23, pp. 105-114, 2020.

42. Y. Li, T. Ma, R. Wang, P. Chen, and Q. Zhang, “Terrain Correlation Correction Method for AUV Seabed Terrain Mapping," Journal of Navigation, vol. 70, pp. 1062-1078, 2017.

43. S. Jiang, "Marine internet for internetworking in oceans: A tutorial," Future Internet, vol. 11, p. 146, 2019.

44. M. J. P. Saiz, "Study and development of a Submarine Optical Communication: TCP Protocol," 2018.

45. E. D. Wardihani, E. Purbawati, and E. Supriyanto, "Analysis of multi-source effect in underwater communication," in 2017 IEEE International Conference on Communication, Networks and Satellite (Comnetsat), 2017, pp. 67-73.

46. A. Khoiro, I. Arifin, M. Pratama, and M. F. Adianto, "Design and Development Graphical User Interface on Inertial Navigation System of Submarine," IPTEK Journal of Proceedings Series, pp. 62-67, 2019.

47. S. S and B. Maram, "Underwater Wireless Sensor Networks," 2018, vol. 2, p. 3, 2018-01-05 2018.

48. V. Khajuria and M. Kaur, "Underwater Wireless Sensor Network: Architecture, Applications and Challenges," in 2018 2nd International Conference on Trends in Electronics and Informatics (ICOEI), 2018, pp. 939-944.

49. B. Zerr, L. Jaulin, V. Creuze, N. Debese, I. Quidu, B. Clement, et al., Quantitative Monitoring of the Underwater Environment vol. 6: Springer, 2016.

50. S. Jiang, F. Liu, and S. Jiang, "Distance-alignment based adaptive MAC protocol for underwater acoustic networks," in 2016 IEEE Wireless Communications and Networking Conference, 2016, pp. 1-6.

51. J. Goh, A. Shaw, and A. Al-Shamma'a, "Underwater wireless communication system," in Journal of Physics: Conference Series, 2009, p. 012029. 
52. G. Mazurek, "Basic channel parameters of ultrasound transmission in air," in 2018 22nd International Microwave and Radar Conference (MIKON), 2018, pp. 607-609.

53. E. Demirors, D. Unal, G. E. Santagati, and T. Melodia, "High-Data Rate Carrierless Impulsive Communications For Underwater Acoustic Networks," in Underwater Acoustics Conference and Exhibition, 2019.

54. A. Krivchenkov and A. Skrunds, "Measurements of the Parameters of a Broadband Satellite Data Channel in the SEVSAT Ship System," Cham, 2019, pp. 440-449.

55. I. I. Lysogor, L. S. Voskov, and S. G. Efremov, "Survey of data exchange formats for heterogeneous LPWAN-satellite IoT networks," in 2018 Moscow Workshop on Electronic and Networking Technologies (MWENT), 2018, pp. 1-5.

56. S. N. Rao, D. Raj, V. Parthasarathy, S. Aiswarya, M. V. Ramesh, and V. Rangan, "A novel solution for high speed internet over the oceans," in IEEE INFOCOM 2018 - IEEE Conference on Computer Communications Workshops (INFOCOM WKSHPS), 2018, pp. 906-912.

57. K. Korcz, "19. Yesterday, Today and Tomorrow of the GMDSS," International Recent Issues about ECDIS, $e$-Navigation and Safety at Sea: Marine Navigation and Safety of Sea Transportation, p. 149, 2017.

58. B. Bellalta, "IEEE 802.11ax: High-efficiency WLANS," IEEE Wireless Communications, vol. 23, pp. 38-46, 2016.

59. J. Ge, T. Li, and T. Geng, "The Wireless Communications for Unmanned Surface Vehicle: An Overview," Cham, 2018, pp. 113-119.

60. J. Kim, S. Koo, and G. Lee, "Comparison of Speed by Type of Wireless LAN," in Proceedings of the Korean Institute of Information and Commucation Sciences Conference, 2018, pp. 19-20.

61. S. Park, J. Kim, S. Yun, and J. Choi, "SIGNAL TRANSMISSION/RECEPTION METHOD IN WIRELESS LAN SYSTEM, AND DEVICE THEREFOR," ed: US Patent App. 16/461,351, 2020.

62. K. Korcz, "Maritime radio information systems," Journal of KONES, vol. 24, 2017.

63. S. Mun, J. Son, W. Jo, and W. Lee, "An implementation of AIS-based ad hoc routing (AAR) protocol for maritime data communication networks," in 2012 8th International Conference on Natural Computation, 2012, pp. 1007-1010.

64. F. Lázaro, R. Raulefs, W. Wang, F. Clazzer, and S. Plass, "VHF Data Exchange System (VDES): an enabling technology for maritime communications," CEAS space Journal, vol. 11, pp. 55-63, 2019 .
65. I. Recommendation, “2092-0, Technical characteristics for a VHF data exchange system in the VHF maritime mobile band," International Telecommunication Union, Geneva, 2015.

66. P. H. Putman, "Display Interfacing 2018: Getting Around the UHD Speed Bump," SMPTE Motion Imaging Journal, vol. 127 , pp. 51-55, 2018.

67. D. Anderson and J. Trodden, USB 3.0 Technology: MindShare Press, 2013.

68. A. Sadat, M. Campbell, H. Ali, and Z. Lin, "Alternate Mode for USB Type-C $\mathrm{C}^{\mathrm{m}}$ : Going beyond USB," Texas Instruments, 2016.

69. A. Li, "USB Type-C for Machine Vision," Quality, pp. 16VS-17VS, 2018.

70. J. C. R. Guerrero, I. B. Mabrouk, M. Alhassan, M. Nedil, and T. Ciamulski, "On the Path Loss Model for 5-GHz Microwave-Based Pinless Subsea Connectors," Progress In Electromagnetics Research, vol. 82, pp. 147-153, 2019.

71. WiSub. (2018, 13/09/2020). High Performance Pinless Subsea Connector. Available: https://wisub.com/wp-content/ uploads/2018/08/wisub_maelstrom_product_data_sheet_ rD_web.pdf

72. R. A. Atmoko, D. Yang, M. Y. Alfiani, and L. Subiyanto, "Controlling Unmanned Surface Vehicle Using MQTT Protocol," Journal Of Computer Networks, Architecture and High Performance Computing, vol. 1, pp. 21-28, 2019.

73. A. L. Christensen, S. Oliveira, O. Postolache, M. J. o. De Oliveira, S. Sargento, P. Santana, et al., "Design of Communication and Control for Swarms of Aquatic Surface Drones," in ICAART (2), 2015, pp. 548-555.

74. G. B. Laleci, G. Aluc, A. Dogac, A. Sinaci, O. Kilic, and F. Tuncer, "A semantic backend for content management systems," Knowledge-Based Systems, vol. 23, pp. 832-843, 2010/12/01/ 2010 .

75. M. Kaluža, M. Kalanj, and B. Vukelić, "A Comparison of Back-end Frameworks for Web Application Development," Zbornik Veleučilišta u Rijeci, vol. 7, pp. 317-332, 2019.

76. Y. Carreno, È. Pairet, Y. Petillot, and R. P. Petrick, “Task Allocation Strategy for Heterogeneous Robot Teams in Offshore Missions," in Proceedings of the 19th International Conference on Autonomous Agents and MultiAgent Systems, 2020, pp. 222-230.

77. F. Thompson and D. Guihen, "Review of mission planning for autonomous marine vehicle fleets," Journal of Field Robotics, vol. 36, pp. 333-354, 2019. 
78. Z. Raja Jawwad, M. Chakkol, M. Johnson, and A. Beltagui, "Organizing for servitization: examining front- and back-end design configurations," International Journal of Operations \& Production Management, vol. 38, pp. 249-271, 2018.

79. H. Hastie, X. Liu, and P. Patron, "A demonstration of multimodal debrief generation for AUVs, post-mission and in-mission," presented at the Proceedings of the 18th ACM International Conference on Multimodal Interaction, Tokyo, Japan, 2016.

80. H. Hastie, X. Liu, Y. Petillot, and P. Patron, "Talking autonomous vehicles: Automatic AUV mission analysis in natural language," in OCEANS 2017 - Aberdeen, 2017, pp. 1-5.

81. H. Poranen, G. Marafioti, G. Johansen, and E. Sæter, "User Interface Design Guidelines for Marine Autonomous Operations Involving a Large Number of Actors, Devices and Sensors," in ASME 2018 37th International Conference on Ocean, Offshore and Arctic Engineering, 2018.

82. N. K. Yilmaz, C. Evangelinos, P. F. Lermusiaux, and N. M. Patrikalakis, "Path planning of autonomous underwater vehicles for adaptive sampling using mixed integer linear programming," IEEE Journal of Oceanic Engineering, vol. 33, pp. 522-537, 2008.

83. K. Zhang, J. Du, J. Wang, C. Jiang, Y. Ren, and A. Benslimane, "Distributed hierarchical information acquisition systems based on auv enabled sensor networks," in ICC 2019-2019 IEEE International Conference on Communications (ICC), 2019, pp. 1-6.

84. C. Yu, X. Xiang, F. Maurelli, Q. Zhang, R. Zhao, and G. Xu, "Onboard system of hybrid underwater robotic vehicles: Integrated software architecture and control algorithm," Ocean Engineering, vol. 187, p. 106121, 2019/09/01/ 2019.

85. A. Atyabi, S. MahmoudZadeh, and S. Nefti-Meziani, "Current advancements on autonomous mission planning and management systems: An AUV and UAV perspective," Annual Reviews in Control, vol. 46, pp. 196-215, 2018/01/01/ 2018.

86. J.-M. Kwak, S.-H. Kim, and S.-R. Lee, "Design of marine IoT wireless network for building fishing gear monitoring system," The Journal of Advanced Navigation Technology, vol. 22, pp. 76-83, 2018.

87. A. Nordrum, "A language for the internet of underwater things [News]," IEEE Spectrum, vol. 54, pp. 9-10, 2017.

88. C. Petrioli, R. Petroccia, D. Spaccini, A. Vitaletti, T. Arzilli, D. Lamanna, et al., "The SUNRISE GATE: Accessing the SUNRISE federation of facilities to test solutions for the Internet of Underwater Things," in 2014 Underwater Communications and Networking (UComms), 2014, pp. 1-4.
89. L. S. Dalenogare, G. B. Benitez, N. F. Ayala, and A. G. Frank, "The expected contribution of Industry 4.0 technologies for industrial performance," International Journal of Production Economics, vol. 204, pp. 383-394, 2018/10/01/ 2018.

90. M. Nitti, R. Girau, L. Atzori, and V. Pilloni, "Trustworthiness management in the IoT: The importance of the feedback," in 2017 20th Conference on Innovations in Clouds, Internet and Networks (ICIN), 2017, pp. 325-327.

91. C. Costa, E. Fanelli, S. Marini, R. Danovaro, and J. Aguzzi, "Global Deep-Sea Biodiversity Research Trends Highlighted by Science Mapping Approach," Frontiers in Marine Science, vol. 7 , p. 384, 2020.

92. C. M. Harris, Handbook of acoustical measurements and noise control: McGraw-Hill New York, 1991.

93. C. J. Deepu, C.-H. Heng, and Y. Lian, "A hybrid data compression scheme for power reduction in wireless sensors for IoT,' IEEE transactions on biomedical circuits and systems, vol. 11, pp. 245-254, 2016.

94. S.-W. Jo, J. H. Jang, S. Yu, and W. Shim, "A Validation of Field Test Results for LTE-Maritime," IFAC-PapersOnLine, vol. 51, pp. 153-158, 2018/01/01/ 2018.

95. G. Aloi, G. Caliciuri, G. Fortino, R. Gravina, P. Pace, W. Russo, et al., "A Mobile Multi-Technology Gateway to Enable IoT Interoperability," in 2016 IEEE First International Conference on Internet-of-Things Design and Implementation (IoTDI), 2016, pp. 259-264.

96. G. Xu, W. Shen, and X. Wang, "Applications of Wireless Sensor Networks in Marine Environment Monitoring: A Survey," Sensors, vol. 14, pp. 16932-16954, 2014.

97. G. Xu, W. Shen, and X. Wang, "Marine environment monitoring using Wireless Sensor Networks: A systematic review," in 2014 IEEE International Conference on Systems, Man, and Cybernetics (SMC), 2014, pp. 13-18.

98. M. Dener and C. Bostancioğlu, "Smart technologies with wireless sensor networks," Procedia-Social and Behavioral Sciences, vol. 195, pp. 1915-1921, 2015.

99. M. A. Kafi, J. B. Othman, and N. Badache, "A Survey on Reliability Protocols in Wireless Sensor Networks," ACM Comput. Surv., vol. 50, p. Article 31, 2017.

100. R. Su, D. Zhang, C. Li, Z. Gong, R. Venkatesan, and F. Jiang, "Localization and Data Collection in AUVAided Underwater Sensor Networks: Challenges and Opportunities," IEEE Network, vol. 33, pp. 86-93, 2019.

101. P. V. Venkateswara Rao, N. Mohan Krishna Varma, and R. Sudhakar, "A Systematic Survey on Software-Defined 
Networks, Routing Protocols and Security Infrastructure for Underwater Wireless Sensor Networks (UWSNs)," Singapore, 2020, pp. 551-559.

102. P. Tan, H. Wu, P. Li, and H. Xu, "Teaching management system with applications of RFID and IoT technology," Education Sciences, vol. 8, p. 26, 2018.

103. S. A. Ahson and M. Ilyas, RFID handbook: applications, technology, security, and privacy: CRC press, 2017.

104. G. Kara, "ANALYSIS OF METEOROLOGICAL FACTORS AFFECTING ON MARITIME TRANSPORT SYSTEMS," PROCEEDINGS BOOK, p. 693, 2016.

105. P. Gupta, J. Batra, J. Sangwan, and A. Khatri, "Marine Monitoring Based on WSN: Application and Challenges," International Journal of Advanced Studies of Scientific Research, vol. 3, 2018.

106. A. Khasawneh, M. S. B. A. Latiff, O. Kaiwartya, and H. Chizari, "Next Forwarding Node Selection in Underwater Wireless Sensor Networks (UWSNs): Techniques and Challenges," Information, vol. 8, p. 3, 2017.

107. H. I. Moud, A. Shojaei, and I. Flood, "Current and future applications of unmanned surface, underwater, and ground vehicles in construction," in Proceedings of the Construction Research Congress, 2018, pp. 106-115.

108. A. E. Pallares-Calvo, B. E. Carvajal-Gámez, and O. O. Gutiérrez-Frías, "Radio beacon for geo-referenced location at sea using mobile devices," in Emerging Imaging and Sensing Technologies for Security and Defence III; and Unmanned Sensors, Systems, and Countermeasures, 2018, p. 107990X.

109. W. Sun, Z. Wei, B. Hong, and Y. Yang, "A Digital Ocean Cloud Platform Architecture Based on IPv6 Smart Gateway," in 2019 IEEE 4th International Conference on Cloud Computing and Big Data Analysis (ICCCBDA), 2019, pp. 438-442.

110. Y. Yang, Z. Wei, and B. Hong, "Research on IPv6 Transition Technology for Digital Ocean," in 2018 IEEE 4th International Conference on Computer and Communications (ICCC), 2018, pp. 317-320.

111. G. Xu, Y. Shi, X. Sun, and W. Shen, "Internet of Things in Marine Environment Monitoring: A Review," Sensors, vol. 19, p. 1711, 2019.

112. B. Kang and H. Choo, "An experimental study of a reliable IoT gateway," ICT Express, vol. 4, pp. 130-133, 2018/09/01/ 2018.

113. S. Yoon and J. Kim, "Remote security management server for IoT devices," in 2017 International Conference on
Information and Communication Technology Convergence (ICTC), 2017, pp. 1162-1164.

114. M. Burhan, R. A. Rehman, B. Khan, and B.-S. Kim, "IoT elements, layered architectures and security issues: A comprehensive survey," Sensors, vol. 18, p. 2796, 2018.

115. Z. Yang, W. Xie, L. Huang, and Z. Wei, "Marine data security based on blockchain technology," IOP Conference Series: Materials Science and Engineering, vol. 322, p. 052028, 2018/03 2018 .

116. A. J. C. Trappey, C. V. Trappey, U. Hareesh Govindarajan, A. C. Chuang, and J. J. Sun, "A review of essential standards and patent landscapes for the Internet of Things: A key enabler for Industry 4.0," Advanced Engineering Informatics, vol. 33, pp. 208-229, 2017/08/01/ 2017.

117. S. Mukherjee, "Collaborative governance strategies for a strategic offshore IT outsourcing engagement," Journal of Global Operations and Strategic Sourcing, vol. 10, pp. 255$278,2017$.

118. L. Chen, "Investing in the IOT-Based Deep Learning that Makes a Competitive Difference: An Industrial View," in 2017 International Conference on Network and Information Systems for Computers (ICNISC), 2017, pp. 205-207. 


\title{
CONTACT WITH THE AUTHORS
}

Pedro Jose Bernalte Sanchez

e-mail:Pedro.Bernalte@uclm.es

University of Castilla-La Mancha

ETII Campus Universitario sn

13004 Ciudad Real

SPAIN

\section{Fausto Pedro García Márquez}

e-mail: faustopedro.garcia@uclm.es

University of Castilla-La Mancha

ETSI Campus Universitario s/n

13071 Ciudad Real

SPAIN

\section{Shashank Govindaraj}

e-mail: shashank.govindaraj@spaceapplications.com

Space Applications Services NV/SA

Sint-Stevens-Woluwe, Brussels Area

Sint-Stevens-Woluwe, 56987 Brussels

\section{BELGIUM}

\author{
Alexandru But \\ e-mail: alexandru.but@spaceapplications.com \\ Space Applications Services NV/SA \\ Sint-Stevens-Woluwe, Brussels Area \\ Sint-Stevens-Woluwe, 56987 Brussels \\ BELGIUM

\section{Benjamin Sportich} \\ e-mail:bsp@spaceapplications.com \\ Space Applications Services NV/SA \\ Sint-Stevens-Woluwe, Brussels Area \\ Sint-Stevens-Woluwe, 56987 Brussels

\section{BELGIUM}

\section{Simone Marini} \\ e-mail: simone.marini@sp.ismar.cnr.it \\ Institute of Marine Sciences \\ National Research Council of Italy (CNR) \\ 789965 La Spezia \\ ITALY \\ Valter Jantara Junior \\ e-mail:V.L.JantaraJunior@bham.ac.uk \\ University of Birmingham \\ Edbaston, 5698745 Birmingham \\ UNITED KINGDOM \\ Mayorkinos Papaelias \\ e-mail:m.papaelias@bham.ac.uk \\ School of Metallurgy and Materials \\ The University of Birmingham, Edgbaston, \\ Birmingham, UK, Edbaston, 5698745 Birmingham,
}

\section{UNITED KINGDOM}

